\title{
Prevalence and Pattern of Congenital Anomalies and Its Outcome at Chattagram Maa-O-Shishu General Hospital
}

\author{
Wazir Ahmed ${ }^{*}$ \\ Dipika Dey ${ }^{1}$ \\ Russel Farid ${ }^{1}$
}

'Department of Neonatalogy Chattagram Maa-O-Shishu Hospital Medical College Chittagong, Bangladesh.

\section{*Correspondence to:}

\section{Professor Wazir Ahmed}

Head, Department of Neonatology \& Director of ICH Chattagram Maa-O-Shishu Hospital Medical College

Chittagong, Bangladesh.

Mobile : +88 01819318768

E-Mail: wazir_neonatology@yahoo.com.

\begin{abstract}
Background: Congenital anomalies are a major cause of perinatal and neonatal deaths, both in low and high-income countries. The aim of the study is to find out the overall incidence of clinically detectable Congenital anomalies in newborns in Chattagram Maa-O-Shishu General Hospital (CMOSH). Methods: A retrospective study was carried out from July 2010 to June 2011 to find out the incidence of congenital anomalies \& its outcome at Chattagram Maa-O- Shishu General Hospital. Results: The total number of admission during this period was 2395 and total number of death was 141, out of which Congenital anomalies were 105. Among the Congenital anomalies, congenital heart disease was 62, Club foot was 9, Down syndrome was 8 , Hydrocephalus was 5, Cleft lip \& cleft palate was 5, Umbilical hernia was 4 , Duodenal atresia was 3 , Tongue tie was 3, Pierre robin syndrome was 3, Hisprung disease was 2 and Mermaid syndrome was 1. Conclusion: Heart defects were the most prevalent anomaly detected. Early prenatal diagnosis is therefore very helpful in decreasing perinatal mortality by allowing for the option of early termination of pregnancy.
\end{abstract}

Key words: Congenital Anomaly; Neonate; WHO.

\section{INTRODUCTION}

A congenital anomaly is a condition which is present at the time of birth which varies from the standard presentation. In 2004, WHO estimates that about 260000 deaths worldwide were caused by congenital anomalies ${ }^{1}$. It is almost $7 \%$ of all neonatal deaths.

It is estimated that $94 \%$ of serious birth defects occur in middle and low-income countries, where mothers are more susceptible to macro and micronutrient malnutrition and have increased exposure to perinatal infection. Advanced maternal age also increases the risk of chromosomal abnormalities such as Down syndrome ${ }^{2-7}$. Congenital anomalies are having a huge impact in contributing to Neonatal and infant mortality and morbidity, developed nations have devised a precise observation system to discover the prevalence of Congenital anomalies for the development of effective preventive systems ${ }^{8}$.

Every 4.5 minutes, a baby is born with a birth defect ${ }^{9}$. Although the worldwide incidence of birth defects is estimated at $3-7 \%$, the rate varies widely between countries ${ }^{10}$. It is reported to be $1.07 \%$ in Japan, $1.49 \%$ in South Africa, $2 \%$ in England, $2-3 \%$ in USA and $4.3 \%$ in Taiwan. In India, the overall incidence of birth defects ranges from $0.3 \%$ to $3.6 \%{ }^{11}$. WHO is working with the US Centers for Disease Control and Prevention's (CDC) National Center on Birth Defects and Developmental Disabilities and other partners for the prevention of birth defects. 
Prevalent studies of congenital anomalies are useful to establish baseline rates, to document changes over time and to identify clues to etiology. They are also important for health services planning and evaluating antenatal screening in populations with high risk. The study is also important as it may help to raise the awareness of surgical pediatric intervention and to emphasize the loss of babies with congenital abnormalities ${ }^{12}$.

Congenital anomalies have a significant role in morbidity and mortality of children ${ }^{13}$. As the management and rehabilitation of these children with congenital abnormality is very costly, it is imperative to identify causative and risk factors and prevent them early where possible ${ }^{14}$.

There are currently no sound estimates of the number of children born with a serious congenital disorder attributable to genetic or environmental causes. Our aim was to discover the frequency of various and common congenital abnormalities in neonates admitted at CMOSH Chittagong, Bangladesh.

\section{MATERIALS AND METHODS}

A retrospective study was conducted to evaluate the incidence of congenital abnormalities among neonates, at the Neonatology Department of CMOSH, Chittagong, Bangladesh from July 2010 to June 2011. In our study, we included all those infants who were diagnosed with at least one birth defect. Information regarding patients was obtained from patient records at the beginning of the study.

\section{RESULTS}

The total number of admission during this period was 2395 and total number of death was $141(5.88 \%)$ out of which Congenital anomalies was $105(4.38 \%)$. Death due to congenital anomalies was 8(5.67\%) (Figure 1).

Among the Congenital anomalies, congenital heart disease was 62(59.04\%) Club foot was $9(8.57 \%)$ Down syndrome was $8(7.61 \%)$ Hydrocephalus was $5(4.76 \%)$ Cleft lip \& cleft palate was $5(4.76 \%)$ Umbilical hernia was $4(3.81 \%)$ Duodenal atresia was $3(2.86 \%)$ Tongue tie was $3(2.86 \%)$ Pierre robin syndrome was $3(2.86 \%)$ Hirschsprung disease was $2(1.90 \%)$ and Mermaid syndrome was 1(1\%) (Table 1).

Among the 105 patients, 80 patients was discharged for further follow up, 17 patients were referred to higher centre and 8 patients died (Table 2). Among them death due to congenital heart disease was $5(62.50 \%)$ Mermaid syndrome $1(12.50 \%)$ Duodenal atresia 1(12.50\%) and Hydrocephalus 1(12.50\%) (Table 3).

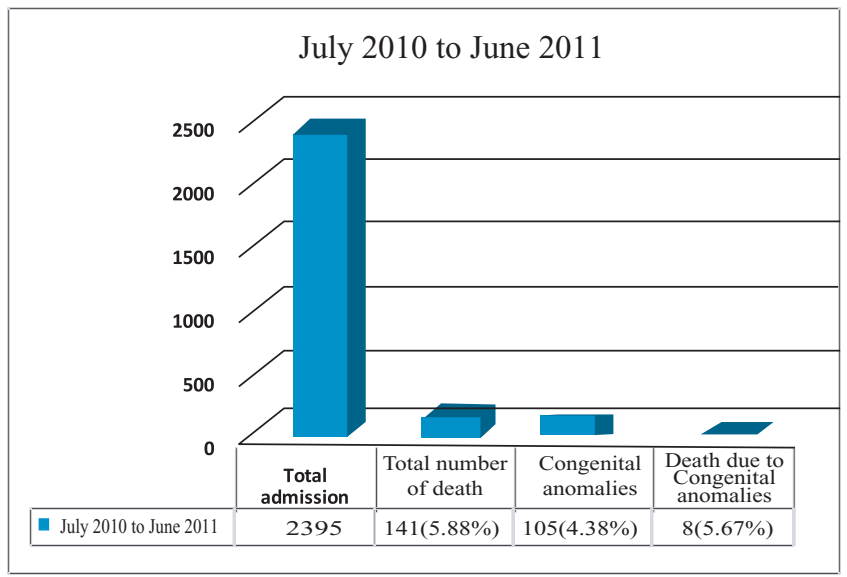

Figure 1: Percentage of Congenital anomalies among study population.

Table 1: Distribution of various congenital anomalies.

\begin{tabular}{lcccc} 
Total Admission: 105 & Total no of patients & Male & Female & Percentage \\
Total Congenital Heart disease & 62 & 42 & 20 & $59.04 \%$ \\
Club foot & 9 & 4 & 5 & $8.57 \%$ \\
Down syndrome & 8 & 5 & 3 & $7.61 \%$ \\
Hydrocephalus & 5 & 3 & 2 & $4.76 \%$ \\
Cleft lip \& cleft palate & 5 & 2 & 3 & $4.76 \%$ \\
Umbilical hernia & 4 & 3 & 1 & $3.81 \%$ \\
Duodenal atresia & 3 & 2 & 1 & $2.86 \%$ \\
Tongue Tie & 3 & 2 & 1 & $2.86 \%$ \\
Pierre robin syndrome & 3 & 3 & 0 & $2.86 \%$ \\
Hirschsprung disease & 2 & 2 & 0 & $1.90 \%$ \\
Mermaid syndrome & 1 & 1 & 0 & $1.00 \%$ \\
Total & 105 & $\mathbf{6 9}$ & $\mathbf{3 6}$ & $\mathbf{1 0 0 \%}$ \\
\hline
\end{tabular}

Table 2: Outcome of various congenital anomalies (Pie chart).

Description Number of patients

Discharged for further follow up

80

Referred to higher centre

Number of death 8

Total

105

Table 3: Distribution of death among congenital anomalies.

Diseases Number of death $(\%)$

Congenital heart disease

$5(62.50 \%)$

Mermaid syndrome

$1(12.50 \%)$

Duodenal atresia

$1(12.50 \%)$

Hydrocephalus

$1(12.50 \%)$

Total

$8(100 \%)$ 


\section{DISCUSSION}

Congenital anomalies are important causes of fetal deaths, thus it becomes mandatory to determine the incidence and prevalence of congenital abnormalities in society. The present study demonstrated the hospital admission of neonate due to congenital anomalies and mortality of neonate related to it in a tertiary care hospital of Chittagong district, Bangladesh.

In the present study, Congenital heart disease was commonest. $62(59.04 \%)$ of congenital anomalies were due to heart defect. Among others Club foot was $9(8.57 \%)$ Down syndrome was $8(7.61 \%)$ Hydrocephalus was $5(4.76 \%)$ Cleft lip \& cleft palate was 5(4.76\%) Umbilical hernia was 4(3.81\%) Duodenal atresia was $3(2.86 \%)$ Tongue tie was $3(2.86 \%)$ Pierre robin syndrome was $3(2.86 \%)$ Hisprung disease was $2(1.90 \%)$ and Mermaid syndrome was $1(1 \%)$. Total death with Congenital anomalies was $8(5.67 \%)$.

A study conducted by Banu T et al 2014 revealed that $44.61 \%$ of all pediatric surgical admission due to birth defect and $51.49 \%$ pediatric death due to birth defect observed in their study period ${ }^{14}$. The most common cause of death was anorectal malformation followed by gastroenteritis.

In the present study, males were more commonly affected than females. Congenital malformations that exist more commonly in males have also been reported in other studies ${ }^{14}$.

Herbert A Obu et al (2012) study revealed that, surgical birth defects are common Congenital anomalies (2.8\%) which comprised of neural tube defect, ano-rectal malformations, cleft lip/cleft palate, limb abnormalities, omphalocoele, umbilical hernia, and dysmorphism accompanying with various Congenital annomalies ${ }^{15}$. This findings is similar to our study.
A hospital-based study conducted in India stated that 1.91\% of neonate born with congenital anomalies ${ }^{16}$. A frequency of congenital anomalies at 29.4/1000 live births reported in another study conducted in Iran ${ }^{17}$. This is also similar with our study; here the incidence of congenital abnormalities are $4.38 \%$. This finding is also similar to the findings of Naderi et al. and Asindi et $\mathrm{al}^{18-19}$.

Central Nervous system anomalies is the most common Congenital anomalies $(58.06 \%)$ were revealed by khan et al study ${ }^{20}$. Among them hydrocephalus, anencephaly and meningomeyecoele are predominant. Few congenital anomalies of hydrocephalus were found in our study.

\section{CONCLUSION}

Since this study was a cross-sectional, retrospective study, the results may not be expected to the entire population. Nevertheless, these results emphasize an important public health issue and present a baseline for other well-designed studies. Heart defects were the most prevalent anomaly detected. Early prenatal diagnosis is therefore very helpful in decreasing perinatal mortality by allowing for the option of early termination of pregnancy. This study contributes to determine the frequency of congenital anomalies at $\mathrm{CMOSH}$, Chittagong. Further studies are required to evaluate interventions that may be oriented to eliminate risk factors and reduce the incidence of congenital anomalies.

\section{DISCLOSURE}

All the authors declared no competing interest. 


\section{REFERENCES}

1. The global burden of disease: 2004 update. Geneva, World Health Organization, 2008

2. Tomatir AG, Demirhan H, Sorkun HC, Koksal A, Ozerdem F, Cilengir N. Major congenital anomalies: A five-year retrospective regional study in Turkey. Genetics and Molecular Research. 2009;8(1):19-27.

3. Harris JA, James L. State-by-state cost of birth defects: 1992. Teratology. 1997;56(1-2): 11-16.

4. Botto LD, Lynberg MC, Erickson JD. Congenital heart defects, maternal febrile illness, and multivitamin use: A population- based study. Epidemiology. 2001;12(5):485-490.

5. Karbasi SA, Golestan M, Fallah R, Mirnaseri F, Barkhordari K, Mahdokht SB. Prevalence of Congenital Malformations in Yazd (Iran) ActaMedicaIranica. 2009; 47(2): 149-153.

6. EUROCAT Working Group (2002). Surveillance of congenital anomalies in Europe 1980-1999. EUROCAT Report 8. University of Ulster, Belfast.

7. Gul F, Jabin M, Khan AS. Frequency of congenital malformations and associated risk factors at Liaqat Memorial Hospital, Kohat. Khyber Med Univ J. 2012;4(3):119-124.

8. Birth Defect. Centers for disease control and prevention. Available at (http://www.cdc.gov/ncbddd/birthdefects/facts.html) Accessed 05.08.2013.

9. Parmar A, Rathod S P, Patel S V, Patel S M. A study of congenital anomalies in newborn. NJIRM. 2010;1(1):13-17.

10. Tomatir AG, Demirhan H, Sorkun HC, Koksal A, Ozerdem F, Cilengir N. Major congenital anomalies: A five-year retrospectiveregional study in Turkey. Genetics and Molecular Research 2009; 8 (1): 19-27.

11. Bangladesh Bureau of Statistics (2011) Population \& housing census 2011. http://www.bbs.gov.bd/WebTestApplication/ userfiles/Image/ Census2011/Bangladesh_glance.pdf. Accessed 21 July 2012.

12. Grover N. Congenital malformations in Shimla. India J Paediatr. 2000;67:249-251.

13. Dutta HK, Bhattacharyya NC, Sarma JN, Giriraj KJ. Congenital malformations in Asam. J Indian AssocPediatr Surg. 2010;15(2):53-55.

14. Banu T, Chowdhury TK, Das SK, Chowdhury MZ, Hoque MM, Rahman MAM. Birth Defects: A Hospital based study in Chittagong, Bangladesh. 2014;13(3):5-10.

15. Obu HA, Chinawa JM, Uleanya ND, Adimora GN, Obi IE.Congenital malformations among newborns admitted in the neonatal unit of a Tertiary Hospital in Enugu, South-East Nigeria : A retrospective study. BMC Research Notes.2012;5:177.

16. Al Arrayed SS. Epidemiology of congenital abnormalities in Bahrain. East Mediterr Health J. 1995;1(2):248-252.

17. Dutta V, Chaturvedi P. Congenital malformations in rural Maharashtra. Indian Pediatr. 2000; 37(9): 998-1001.

18. Malla BK. One year overview study of congenital anatomical malformation at birth in Maternity Hospital, Thapathali, Kathmandu. RathmanduUni Med J. 2007;5:557-560.

19. Asindi AA, Ibia EO, Udo JJ: Mortality pattern in Nigerian children in the1980s. J Trop Med Hyg. 1991;94:152-155.

20. Khan A, Zuhaid M, Fayaz M, Ali F, Khan A, Ullah R, et al. Frequency of congenital anomalies in newborns and its relation to maternal health in a Tertiary Care Hospital in Peshawar, Pakistan. Int J Med Students. 2015;3(1):19-23. 